\title{
Impact of plant domestication on selected nutrient and anti-nutrient compounds in Solanaceae with edible leaves (Solanum spp.)
}

\author{
Lukasz P. Haliński $\cdot$ Anna Topolewska $\cdot$ Anna Rynkowska $\cdot$ Adriana Mika • \\ Maria Urasińska $\cdot$ Mateusz Czerski $\cdot$ Piotr Stepnowski
}

Received: 28 March 2018/Accepted: 18 September 2018/Published online: 1 October 2018

(C) The Author(s) 2018

\begin{abstract}
Several African Solanum species, including scarlet eggplant (Solanum aethiopicum L.) and the gboma eggplant (S. macrocarpon L.), are recently domesticated green leafy vegetables. The aim of the study was to determine if domestication process affected the amounts of selected nutrient and antinutrient compounds in plant lines bearing edible and inedible leaves in comparison to their wild relatives. Leaves from fourteen accessions of five Solanum species were evaluated for phenolics (385-1002 mg gallic acid equivalent/100 $\mathrm{g}$ dry weight), fatty acid (0.9-3.2 g/100 g DW), sterol (32-99 mg/100 g DW), saponin and glycoalkaloid content $(0-1000 \mathrm{mg}$ and 0-55 mg/100 g DW, respectively, expressed as aglycone content). There were no significant differences between plants with edible and inedible leaves. Similarly, wild and domesticated plants produced comparable amounts of nutrient and anti-nutrient compounds, with exception of wild S. anguivi Lam., which displayed fatty acid content higher than other
\end{abstract}

Electronic supplementary material The online version of this article (https://doi.org/10.1007/s10722-018-0699-1) contains supplementary material, which is available to authorized users.

Ł. P. Haliński $(\bowtie) \cdot$ A. Topolewska .

A. Rynkowska · A. Mika - M. Urasińska .

M. Czerski · P. Stepnowski

Department of Environmental Analysis, Faculty of

Chemistry, University of Gdańsk, Wita Stwosza 63,

80-308 Gdańsk, Poland

e-mail: lukasz.halinski@ug.edu.pl species. The gboma eggplant complex (S. macrocarpon-S. dasyphyllum Schum. et Thonn.) had lower anti-nutrient and phenolics content than scarlet eggplant (S. aethiopicum-S. anguivi). Semi-domesticated S. scabrum Mill. revealed high anti-nutrient and low nutrient production. Selection based on plant morphology is then suggested as the dominating mechanism at the early stage of domestication of African solanaceous plants.

Keywords Domestication - Green leafy vegetables · Solanaceae · Solanum aethiopicum L. · Solanum macrocarpon L. · Morphology

\section{Introduction}

The domestication of plants was one of the most important innovations, that allowed the transition from hunter-gatherer societies to settled agriculture (Meyer et al. 2012; Purugganan and Fuller 2009). The domesticated species are distinct from their wild ancestors in terms of the their morphology and physiology. The morphological diversity may not reflect the genetic variation: the example of Brassica oleracea L. clearly shows that the morphology of certain plant cultivars or subspecies depends on their usage in agriculture (Diamond 2002). The plant domestication process can be seen as a type of plantanimal co-evolution, driven by the selection of traits 
that are desired in agriculture (Purugganan and Fuller 2009). These traits are chosen to make the crop growing easier, but are also connected with local preferences for certain taste, aroma or appearance. It is well-established that the traits preferred in plant domestication are under control of relatively small number of genes (Meyer et al. 2012). Also, the variety of morphological forms is usually not associated with the genetic diversity (Lester and Daunay 2001). Based on the screening of more than 200 domesticated plant species, the most common differences between domesticated and wild plants concern their secondary metabolism (e.g. the lower amounts of toxins and bitter compounds) and the morphology of their aerial parts-mostly leaves, stems and fruits (Meyer et al. 2012).

Among all studies concerning the domestication of plant species used in agriculture, the majority focused on several important cereals, which were domesticated quite early in the history (Meyer et al. 2012; Purugganan and Fuller 2009). Some of the features of these plants, including the loss of seed shattering and multiple origin of domestication, are not very common when non-cereal plant species are concerned. Thus, the results of studies on the domestication of plants from Poaceae family may not be representative for plants of different taxonomic position. The useful model species in the studies on the domestication of plants belonging to other families should be domesticated quite recently and their wild progenitors should be known. Also, a wide variation in plant morphology, which would reflect the different uses of certain lines/ cultivars in agriculture, would be of interest. West Africa is believed to be one the most active centres of plant domestication in last 500 years (Meyer et al. 2012). The group of plants from Solanaceae family cultivated for edible leaves is among relatively new African species used in agriculture (Lester and Daunay 2001). They belong to indigenous vegetable crops, which are grown and consumed in Africa as valuable sources of nutrients (Uusiku et al. 2010). These plants are well adapted to the local climate, including high temperatures and seasonal water deprivation. Almost all of the cultivated plant species from this group have a known wild progenitor, there are also wild and weedy forms, which are also used as a source of food or in traditional medicine. These facts give a unique opportunity to observe changes associated with the domestication of these species. Formally, most of the species belong to genus Solanum, subgenus Leptostemonum (so-called 'spiny Solanum'). They all differ from wild progenitors in their morphology, but are not very distinct genetically (Meyer et al. 2012). The example of such a species is the gboma eggplant (Solanum macrocarpon L.), which is one of the most important solanaceous crops, grown in the humid parts of Africa (Bukenya and Bonsu 2004). Both the leaves and fruits of $S$. macrocarpon are edible when cooked and are eaten as ingredients of soups and sauces, mixed with meat or other vegetables (Gbile and Adesina 1988; Lester and Daunay 2001). While the leaves are usually eaten shortly after the harvest, they can also be sun-dried and stored for future use (Glew et al. 2010; Oboh and Akindahunsi 2004). The gboma eggplant is derived from the wild, spiny African plant S. dasyphyllum Schum. et Thonn.; nevertheless, both plants are fully crossable and may well belong to a single species (Bukenya and Carasco 1994; Haliński et al. 2017). Scarlet eggplant (S. aethiopicum L.) and its wild ancestor ( $S$. anguivi Lam.), while much more diverse morphologically, were also suggested to be genetically and taxonomically very similar (Haliński et al. 2017; Stedje and Bukenya-Ziraba 2003), which was recently confirmed by Acquadro et al. (2017). The cultivated plants can be divided into three main groups: Gilo group is grown for its fruits, Shum group — for edible leaves, and Kumba group — for both fruits and leaves (Lester and Daunay 2001; Lester and Seck 2004). The presence of groups grown for fruits or leaves, as well as the enormous morphological variability, make $S$. aethiopicum an ideal model plant in domestication studies. Some species from other subgenera are also grown for edible leaves and fruits: $S$. scabrum Mill., which is closely related to the common European black nightshade (S. nigrum L.) and placed in subgenus Solanum, section Solanum (Lester and Daunay 2001), is widely used as a source of food (Manoko et al. 2008), but it is still hardly distinguishable from the wild form, which is also utilized. Thus, it is probably on a very first stage of domestication process.

The above-mentioned species are commonly used as a source of edible leaves. The main hypothesis assumes that during the domestication process, some useful plant traits were preferred and selected. These included, among others: (1) the reduction of primitive traits such as the presence of prickles and trichomes; (2) low amount of toxins in leaves; (3) high nutritional 
value of the leaves. It could be assumed that the selection of these traits is limited to the lines grown for edible leaves. However, it was already suggested that at early stage of plant domestication, the selection is based simply on preserving the most valuable individuals and often without intention to alter the plant in some specific way (Heiser 1988; Zohary 2004). This so-called unconscious selection may apply to the majority of plant traits that could be considered beneficial, including toxin content and nutritional values. Alternatively, in case of Solanum species, it is possible that the primary selection (in this case, conscious or methodical one) was made mostly basing on the amount of protective prickles and trichomes, which were reduced in plants grown by man in order to make them easier to collect and eat. Therefore, on the early stage of the domestication, there might be no significant difference in the metabolite profile, including both nutritionally valuable compounds and possible toxins. Because of the above-mentioned facts, the aim of the study was to evaluate differences in the amount of selected nutrient (phenolic compounds, fatty acids, sterols) and anti-nutrient compounds (saponins, glycoalkaloids) in edible and inedible leaves of several wild and cultivated African Solanum species.

\section{Materials and methods}

\section{Plant material}

Four accessions of the Gboma eggplant (S. macrocarpon) and one accession of its wild ancestor ( $S$. dasyphyllum), five accessions of the scarlet eggplant ( $S$. aethiopicum) from different groups and two accessions of its wild ancestor (S. anguivi), and two accessions of $S$. scabrum were used in the study. Seeds were obtained from the CGN-Centre for Genetic Resources, the Netherlands (Wageningen, the Netherlands). The detailed list of accessions is given in Table 1.

The plants were grown from May to September in an unheated greenhouse (temperature $18-32{ }^{\circ} \mathrm{C}$ during the day and between 15 and $20^{\circ} \mathrm{C}$ at night; no supplemental lighting was provided). Standard garden soil was used ( $\mathrm{pH}$ 5.5-6.5; NPK: 14-16-18, $0.6 \mathrm{~kg} \mathrm{~m}^{-3} ; \mathrm{NaCl}$ max. $1.9 \mathrm{~g} \mathrm{dm}^{-3}$ ). Five-week-old plants were transferred to $10 \mathrm{dm}^{3}$ pots, which were kept well-watered by irrigating them 3 times a week (ca. $600-800 \mathrm{~mL}$ of water, depending on the weather conditions). All leaves from three to four 14- to 16-week-old plants of each cultivar were harvested; only the 2-4 oldest and most damaged leaves of each plant were discarded. Leaves were then dried in electric oven at $70{ }^{\circ} \mathrm{C}$ for $3 \mathrm{~h}$. While such an approach could lead to some loss of the most labile compounds, it was designed to simulate sun-drying, which is often applied to leafy vegetables in Africa in order to keep them for the future use (Oboh and Akindahunsi 2004). Seeds of fenugreek (Trigonella foenum-graecum L.), that were used as a source of steroidal sapogenins for their identification using GC-MS, were obtained at the local market.

\section{General experimental procedures}

Derivatization agents: $\mathrm{N}, \mathrm{O}$-bis(trimethylsilyl)trifluoroacetamide (BSTFA) $+1 \%$ trimethylchlorosilane (TMCS), $2.0 \mathrm{M}$ solution of (trimethylsilyl)diazomethane in hexane (TMSD), trifluoroacetic anhydride (TFAA) and pentafluoropropionic anhydride (PFPAA), as well as 2,2-diphenyl-1-picrylhydrazyl (DPPH), gallic acid and nonadecanoic acid ethyl ester were purchased from Sigma-Aldrich Poland (Poznań, Poland). $\quad N$-methyl- $N$-(trimethylsilyl)trifluoroacetamide (MSTFA) was obtained from MachereyNagel (Düren, Germany) and L-ascorbic acid (99.7\%) from Riedel-de-Haën (Seelze, Germany). Folin-Ciocalteu reagent was purchased from POCh S.A. (Gliwice, Poland). Glycoalkaloid and aglycone standards: $\alpha$-solanine, $\alpha$-tomatine $(>95 \%)$ and solasodine were purchased from Santa Cruz Biotechnology (Dallas, Texas, USA). All the other chemicals were analytical grade and were obtained from POCh S.A. (Gliwice, Poland), Stanlab (Lublin, Poland) or Chempur (Piekary Śląskie, Poland).

Total phenolic compounds and radical-scavenging activity were determined using Beckman DU 650 UVVis spectrophotometer (Beckman, Brea, California, USA). Fatty acids, sterols, steroidal sapogenins and aglycones of steroidal glycoalkaloids were identified by gas chromatography-mass spectrometry (GCMS), using Shimadzu GCMS-QP2010 SE (Shimadzu, Kyoto, Japan) single quadrupole system. All GC-MS experiments were carried out using electron ionization (70 eV, ion source temperature $200{ }^{\circ} \mathrm{C}$ ), with helium as carrier gas at a flow rate of $1 \mathrm{~mL} \mathrm{~min}^{-1}$. 
Table 1 Summary of the Solanum species and accessions used in the study; all the accessions were obtained from the CGN-Centre for Genetic Resources (the Netherlands)

\begin{tabular}{|c|c|c|c|c|}
\hline Species & Symbol & Cultivar & Origin & Accession \\
\hline S. macrocarpon & M1 & RNL 096 & Togo & CGN23660 \\
\hline S. macrocarpon & M2 & RNL 043 & Togo & CGN23661 \\
\hline S. macrocarpon & M3 & RNL 042 & Togo & CGN23687 \\
\hline S. macrocarpon var. sapinii & M4 & - & $\mathrm{nd}^{\mathrm{c}}$ & CGN17504 \\
\hline S. dasyphyllum & D1 & - & Togo & CGN23600 \\
\hline S. aethiopicum, group Aculeatum & AA1 & S.0344 & nd & CGN23319 \\
\hline S. aethiopicum, group Gilo & AG1 & Kana & Togo & CGN23592 \\
\hline S. aethiopicum, group Gilo & AG2 & RNL 103 & Togo & CGN23842 \\
\hline S. aethiopicum, group Kumba & AK1 & Kammona rouge & Togo & CGN23595 \\
\hline S. aethiopicum, group Kumba & AK2 & Akana & Togo & CGN23828 \\
\hline S. anguivi & An1 & S.0871 & Uganda & CGN23848 \\
\hline S. anguivi & An2 & - & nd & CGN23850 \\
\hline S. scabrum ${ }^{\mathrm{a}}$ & $\mathrm{Sc} 1$ & - & nd & CGN23584 \\
\hline S. scabrum $^{\mathrm{b}}$ & Sc2 & Rakouti (Losso); RNL 050 & Togo & CGN23671 \\
\hline
\end{tabular}

${ }^{\text {a}}$ Wild population

${ }^{\mathrm{b}}$ Land variety

${ }^{\mathrm{c}}$ No data

Sapogenins and aglycones were quantified using the same apparatus, while fatty acids and sterols were subjected to GC analysis with flame ionization detector (GC-FID), using Clarus 500 gas chromatograph (Perkin-Elmer Instruments, Waltham, Massachusetts, USA). Argon was used as carrier gas at a flow rate of $1 \mathrm{~mL}$ min $^{-1}$. GC-MS system was equipped with a $30 \times 0.25 \mathrm{~mm}$ i.d., film thickness $0.25 \mu \mathrm{m}$, Zebron5MS WCOT capillary column (Phenomenex, Torrance, California, USA), while GC-FID was equipped with a RTX-5 WCOT capillary column (Restek, Bellefonte, Pennsylvania, USA) of the same size.

Total phenolic compounds and antioxidant properties

Methanolic extracts of dried leaves grounded to the powder using electric mill were prepared by adding $40 \mathrm{~mL}$ methanol to $0.1 \mathrm{~g}$ of plant material. The extraction was performed for $30 \mathrm{~min}$ at room temperature in ultrasonic bath. Then, extracts were filtered and their volume was set to $50 \mathrm{~mL}$ to adjust the amount of plant material extracted to $2 \mathrm{mg} \mathrm{mL}^{-1}$ (on dry basis).
The amount of total phenolic compounds was determined using Folin-Ciocalteu $(\mathrm{F}-\mathrm{C})$ reagent by a modified method originally reported by Singleton and Rossi (1965). Briefly, $0.1 \mathrm{~mL}$ of each extract was mixed with $2 \mathrm{~mL}$ of water and $0.2 \mathrm{~mL}$ of $\mathrm{F}-\mathrm{C}$ reagent, shaken and left at room temperature for $3 \mathrm{~min}$. Then, $0.5 \mathrm{~mL}$ of saturated sodium carbonate solution was added and samples were incubated at $40{ }^{\circ} \mathrm{C}$ for $30 \mathrm{~min}$. Absorbance was measured at $765 \mathrm{~nm}$ against a blank sample prepared in the same way, but using $0.1 \mathrm{~mL}$ of methanol instead of plant extract. Calibration curve was prepared using solutions of gallic acid in a range of $0.01-0.3 \mathrm{mg} \mathrm{mL}^{-1}$ and the results were expressed as gallic acid equivalent (GAE).

The antioxidant activity of extracts was determined by DPPH radical-scavenging activity, as originally proposed by Blois (1958), using slightly modified method described by Brand-Williams et al. (1995). Briefly, $1.5 \mathrm{~mL}$ of methanol and $0.5 \mathrm{~mL}$ of freshly prepared methanolic DPPH solution $\left(0.08 \mathrm{mg} \mathrm{mL}^{-1}\right)$ was added to $0.5 \mathrm{~mL}$ of each extract. Reference sample ( $0 \%$ inhibition) was prepared in the same way, but using $0.5 \mathrm{~mL}$ of methanol instead of plant extract. After $30 \mathrm{~min}$, absorbance was measured at $517 \mathrm{~nm}$ against blank (methanol). The results were expressed 
as ascorbic acid equivalent (AAE), basing on the calibration curve prepared using solutions of ascorbic acid in a range of $0.00125-0.02 \mathrm{mg} \mathrm{mL}^{-1}$.

Fatty acid and sterol analysis

Lipids were extracted from the powdered plant material $(0.25 \mathrm{~g})$ using Folch method (Folch et al. 1957). Prior to extraction, known amount of internal standard (ethyl ester of nonadecanoic acid) was added to the plant material. Extraction was performed for $30 \mathrm{~min}$ at room temperature in ultrasonic bath, using $100 \mathrm{~mL}$ of the chloroform-methanol mixture $(2: 1, \mathrm{v} /$ $v)$. Extracts were then filtered and solvent was evaporated to dryness under reduced pressure and under a stream of nitrogen. Next, $0.15 \mathrm{~mL}$ of $0.3 \mathrm{M}$ methanolic $\mathrm{KOH}$ solution was added and lipids were hydrolyzed at $70{ }^{\circ} \mathrm{C}$ for $3 \mathrm{~h}$. Samples were then acidified using $6 \mathrm{M} \mathrm{HCl}$ and $0.5 \mathrm{~mL}$ of water was added. Fatty acids and sterols liberated from lipids were extracted thrice using $1 \mathrm{~mL}$ of $n$-hexane. Combined organic phases were dried using anhydrous sodium sulphate and solvent was evaporated to dryness under a stream of nitrogen.

Two-step derivatization was performed in order to obtain fatty acid methyl esters and trimethylsilyl (TMSi) derivatives of sterols. First, methyl esters were synthesized using TMSD as described by Topolewska et al. (2015). Briefly, $0.125 \mathrm{~mL}$ of methanol, $0.05 \mathrm{~mL}$ of toluene and $0.05 \mathrm{~mL}$ of TMSD solution was added. The reaction was performed at $90{ }^{\circ} \mathrm{C}$ for $30 \mathrm{~min}$. Next, solvents and reagents were removed under a stream of nitrogen and $0.1 \mathrm{~mL}$ of BSTFA-TMCS mixture $(99: 1, v / v)$ was added. Trimethylsilylation was performed at $90{ }^{\circ} \mathrm{C}$ for $30 \mathrm{~min}$. Samples were derivatized in the day of analysis.

All GC-MS experiments were carried out in the following conditions: oven temperature programmed from 100 to $310{ }^{\circ} \mathrm{C}$ at $4{ }^{\circ} \mathrm{C} \min ^{-1}$ and then kept for $5 \mathrm{~min}$ at $310^{\circ} \mathrm{C}$; injector and transfer line temperatures were set at $310^{\circ} \mathrm{C}$. Similarly, GC-FID conditions were: oven temperature programmed from 100 to $320{ }^{\circ} \mathrm{C}$ at $4{ }^{\circ} \mathrm{C} \min ^{-1}$ and then kept for $5 \mathrm{~min}$ at $320{ }^{\circ} \mathrm{C}$; the injector and detector temperatures were set at $320^{\circ} \mathrm{C}$. Compounds were identified basing on their mass spectra from GC-MS analysis (Goad and Akihisa 1997) and retention parameters from GC analysis. Quantitative analysis of the compounds was based on their peak areas from the GC-FID analysis, compared to the peak area of the internal standard.

Saponin and glycoalkaloid analysis

Saponins and glycoalkaloids were subjected to ultrasound-assisted extraction from homogenized, dried plant material $(0.1 \mathrm{~g})$ using a modified method previously described by Brown et al. (1999). Briefly, $25 \mathrm{~mL}$ of $5 \%$ aqueous acetic acid was added to the sample and the extraction was performed for $15 \mathrm{~min}$ at room temperature. Extracts were filtered, alkalized with ammonia to $\mathrm{pH} 10$ and separated using $60 \mathrm{~mL} n$ butanol-water mixture $(4: 1, v / v)$. The organic layer was collected and evaporated to dryness under reduced pressure. Then, compounds were re-dissolved in ca. $2 \mathrm{~mL}$ methanol and transferred to 4-mL screwcapped glass vials. Solvent was evaporated to dryness under a stream of nitrogen and $2 \mathrm{~mL}$ of $10 \% \mathrm{HCl}$ solution in methanol was added; hydrolysis was performed for $3 \mathrm{~h}$ at $70{ }^{\circ} \mathrm{C}$. The mixture was then alkalized using ammonia and liberated aglycones and sapogenins were extracted three times using $1 \mathrm{~mL}$ of dichloromethane. Pooled organic layers were washed by water to remove excess of ammonia, dried with anhydrous sodium sulphate and evaporated to dryness under a stream of nitrogen. Initial experiments were performed using known amount of $\alpha$-tomatine as internal standard. Final determinations utilized $\alpha$ tomatine in the analysis of compounds from $S$. aethiopicum, S. anguivi and S. scabrum, while compounds isolated from $S$. macrocarpon and $S$. dasyphyllum were analyzed using $\alpha$-solanine to avoid the presence of tomatidine, which is partially overlapping with the solasodine signal.

Two-step derivatization as described by Laurila et al. (1999) was performed during preliminary experiments. Briefly, samples were first trimethylsilylated using $0.1 \mathrm{~mL}$ MSTFA $\left(30 \mathrm{~min}\right.$ at $60^{\circ} \mathrm{C}$ ). Then, remaining free amine group of tomatidine-like aglycones was transferred to respective pentafluoropropionic derivative by adding $0.015 \mathrm{~mL}$ of pyridine and $0.015 \mathrm{~mL}$ of PFPAA. The reaction was completed within few minutes at room temperature. Final samples were derivatized using similar procedure, but PFPAA was replaced with TFAA in order to obtain trifluoroacetic derivatives instead of pentafluoropropionic ones. 
Sapogenins and aglycones of steroidal glycoalkaloids were analyzed using GC-MS in the following conditions: oven temperature programmed from 220 to $320{ }^{\circ} \mathrm{C}$ at $8{ }^{\circ} \mathrm{C} \mathrm{min}{ }^{-1}$ and then kept for $20 \mathrm{~min}$ at $320{ }^{\circ} \mathrm{C}$; injector and transfer line temperatures were set at $320{ }^{\circ} \mathrm{C}$. Compounds were identified basing on their mass spectra and retention parameters (Akahori et al. 1971; Laurila et al. 1999; Lee et al. 2001; Taylor et al. 1997; Tsukatani et al. 1985). Commercially available solasodine standard was used to confirm its presence in $S$. macrocarpon and $S$. dasyphyllum samples. Sapogenins from fenugreek seeds, which were obtained using above-mentioned procedures, were also used to confirm the identification. Quantitative analysis of the compounds was based on their peak areas, compared to the peak area of the internal standard (tomatidine or solanidine liberated from the internal standard).

\section{Data analysis}

The results were given as the mean \pm standard deviation (SD) from three analyses of each type. The comparison of selected parameters between plants with edible and inedible leaves and between $S$. anguivi-S. aethiopicum and S. dasyphyllum-S. macrocarpon complexes was carried out using unpaired $t$ test for unequal variances (Gnumeric 1.12.9 for Windows; The GNOME Project); significant differences were accepted at $P \leq 0.05$.

\section{Results and discussion}

Plant morphology

A total of 14 accessions belonging to five plant species were used in the study (Table 1). Plants were quite diverse in terms of their morphology: pictures of all accessions studied are given as Supplementary material (Figures S1-S3). Wild S. dasyphyllum (Fig. S1A) was relatively slow-growing plant with a large number of long prickles and a significant number of short nonglandular hairs covering stems and narrow, elongated leaves. In contrast, most of $S$. macrocarpon accessions had broader and bigger leaves with no hairs (Fig. S1CE), only S. macrocarpon var. sapinii (Fig. S1B) was somehow more similar to its wild relative in leaf shape and the presence of hairs. The taxonomic status of $S$. macrocarpon var. sapinii is unclear; it is possible that the accession is in fact erroneously described so-called S. macrocarpon subsp. sapinii (De Wild.) Bitter, which is currently unaccepted heterotypic synonym of the wild ancestral species $S$. dasyphyllum (Vorontsova and Knapp 2018). This, however, requires some more detailed analysis of this plant line. Prickles were present only occasionally: they were covering inflorescence, but not leaves, excluding CGN23661 accession, where some prickles were also present along the midribs of the leaves. In contrast, wild $S$. anguivi and cultivated S. aethiopicum plants (Fig. S2) were much more uniform in terms of overall plant morphology and leaf shape. Their stems and leaves were only occasionally covered with a small number of short prickles, with the only exception of S. aethiopicum group Aculeatum (CGN23319; Fig. S3A-B), having numerous long prickles on all above-ground parts of the plant, which was already reported by Plazas et al. (2014a). The distinct nature of Aculeatum group was, at least to some extent, confirmed also by Acquadro et al. (2017). Much more distant S. scabrum accessions were tall plants with small ovate leaves and no prickles on stems or leaves (Fig. S3C-F).

Total phenolic content and radical-scavenging activity

The amount of total phenolic compounds and radicalscavenging activity of extracts are given in Table 2 . The former (expressed as gallic acid equivalent) differed broadly between accessions: the lowest values below $600 \mathrm{mg} / 100 \mathrm{~g}$ DW were determined for $S$. scabrum and some of $S$. macrocarpon accessions (385-826 mg/100 g DW). The mean value for the latter $(594 \mathrm{mg} / 100 \mathrm{~g} \mathrm{DW})$ was similar to the one determined for a wild related $S$. dasyphyllum species $(557 \mathrm{mg} / 100 \mathrm{~g} \mathrm{DW})$. These results are in good agreement with the value of $590 \mathrm{mg} / 100 \mathrm{~g} \mathrm{DW}$ reported for the sun-dried $S$. macrocarpon leaves and 270-840 mg/100 g DW determined for other African green leafy vegetables treated in the same way (Oboh and Akindahunsi 2004). Much higher amounts of phenolic compounds were observed in selected $S$. aethiopicum accessions (699-1172 mg/100 g DW) with both edible (Kumba group) and inedible (Gilo, Aculeatum groups) leaves. The mean value for this species (906 mg/100 g DW) was slightly higher than the one determined for its wild ancestor $S$. anguivi 
Table 2 Total phenolics as gallic acid equivalent (GAE; mg/100 g DW) and DPPH radical scavenging activity as ascorbic acid equivalent (AAE; mg/100 g DW) of methanolic extracts from the leaves of Solanum species studied; all values are expressed as mean $\pm \mathrm{SD}(\mathrm{n}=3)$

\begin{tabular}{lcc}
\hline Plant accession $^{\mathrm{a}}$ & GAE $(\mathrm{mg} / 100 \mathrm{~g} \mathrm{DW})$ & AAE $(\mathrm{mg} / 100 \mathrm{~g} \mathrm{DW})$ \\
\hline M1 & $826 \pm 110$ & $886 \pm 66$ \\
M2 & $452 \pm 59$ & $621 \pm 71$ \\
M3 & $385 \pm 26$ & $424 \pm 11$ \\
M4 & $715 \pm 93$ & $782 \pm 36$ \\
D1 & $557 \pm 50$ & $550 \pm 10$ \\
AA1 & $878 \pm 135$ & $941 \pm 39$ \\
AG1 & $1172 \pm 30$ & $959 \pm 25$ \\
AG2 & $699 \pm 93$ & $810 \pm 39$ \\
AK1 & $1002 \pm 131$ & $961 \pm 22$ \\
AK2 & $779 \pm 101$ & $679 \pm 33$ \\
An1 & $655 \pm 26$ & $802 \pm 67$ \\
An2 & $946 \pm 122$ & $903 \pm 45$ \\
Sc1 & $588 \pm 96$ & $622 \pm 20$ \\
Sc2 & $502 \pm 44$ & $702 \pm 15$ \\
\hline
\end{tabular}

${ }^{\mathrm{a}}$ Plant accessions as described in Table 1 antioxidant content during domestication of plant species studied. It is not surprising, as there is no simple way of evaluating the amounts of phenolic compounds and antioxidant activity by the consumer and/or farmer. Therefore, conscious selection of these features at the early stage of plant domestication is unexpected, and possibly there is no mechanism of their unconscious selection by a chance.

Fatty acid and sterol content

The chemical composition of fatty acids (FAs) and sterols liberated from lipids extracted from leaves of plant species studied is given in Table 3. The total FA content in $S$. macrocarpon and $S$. dasyphyllum leaves was in a range of 1.5-1.9 g/100 g DW. The composition of the fraction was also similar in both species, with the most abundant FA(18:3), accounting for $50-54 \%$ of total FAs, followed by $\mathrm{FA}(16: 0)$ and FA(18:2), which constituted $17-25 \%$ and $15-23 \%$ of total FAs, respectively. These results are consistent with the reports of Glew et al. (2010) and Haliński et al. (2015), where the FA(18:3) compound was also described as the most abundant one (42-45\%); the total amount of FAs reported in the latter source was, however, slightly higher. Almost identical results were obtained also for S. anguivi and S. aethiopicum, with the only exception of AK1 accession, which displayed much higher amounts of $\operatorname{FA}(18: 2)(29 \%)$ and much smaller contribution of FA(18:3) (38\%). The absolute amounts of FAs in S. aethiopicum leaves were similar 


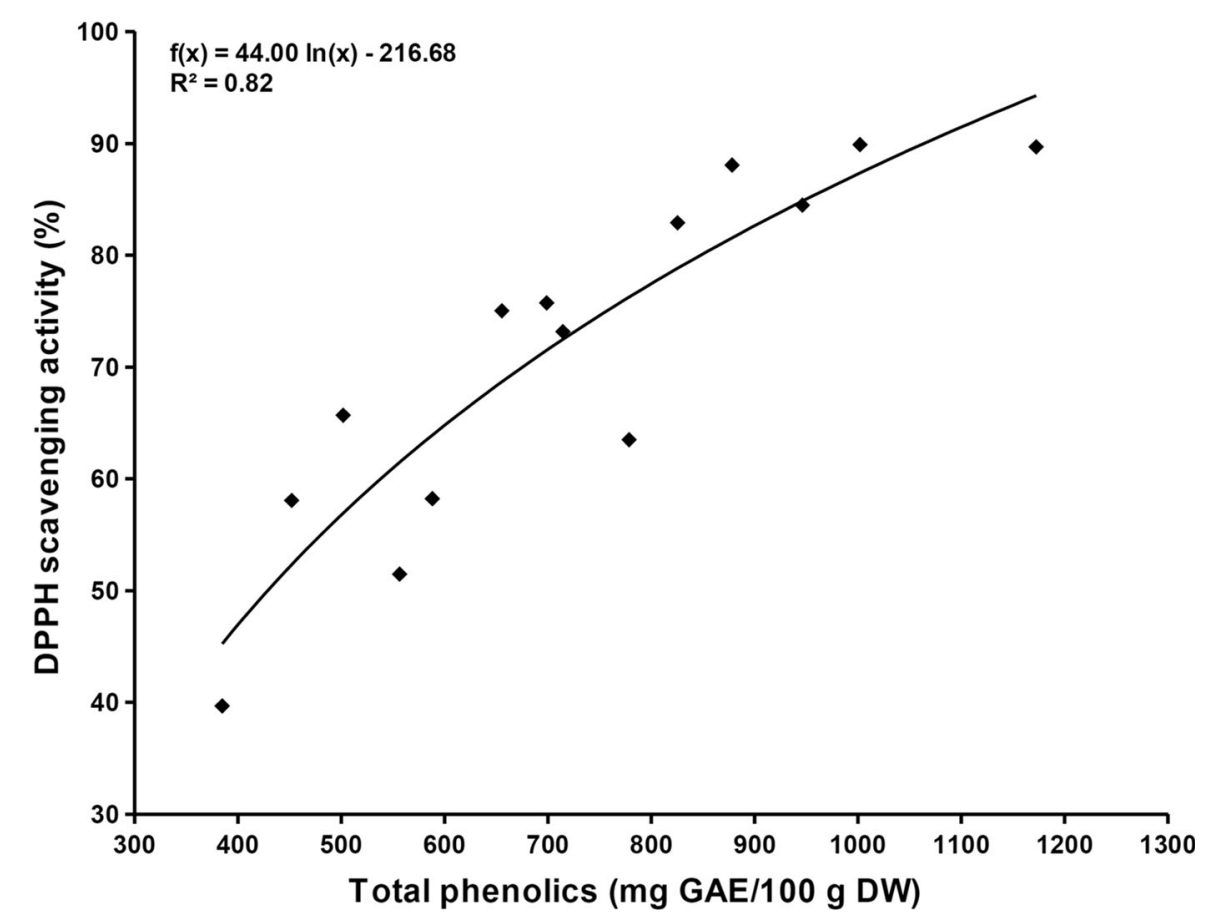

Fig. 1 Correlation between the total content of phenolic compounds in leaves of the plant species studied and scavenging effect of methanolic extracts on DPPH radical

to the ones reported for $S$. macrocarpon (1.4-1.9 g/ $100 \mathrm{~g} \mathrm{DW})$ and did not differ much between plants with edible and inedible leaves. However, the amounts of FAs in wild $S$. anguivi plants were much higher (2.7-3.2 g/100 g DW), suggesting that in case of $S$. aethiopicum-S. anguivi complex, plant domestication was in fact associated with impairing at least some of the nutritional values. Finally, total FA content in $S$. scabrum was the lowest within the whole dataset and did not exceed $1.0 \mathrm{~g} / 100 \mathrm{~g}$ DW. Moreover, the species was also characterized by the lower contribution of $\mathrm{FA}(18: 2)$ and $\mathrm{FA}(18: 3)$ compounds (12-13\% and $42 \%$, respectively), with the highest amounts of saturated fatty acids. Therefore, in terms of lipid composition, S. scabrum could be described as the least valuable among the species studied. Sterols were present in small amounts (less than $0.1 \mathrm{~g} / 100 \mathrm{~g} \mathrm{DW}$ ) in all plant accessions. It was somehow surprising, as there are reports suggesting much higher $(0.3-0.4 \mathrm{~g} /$ $100 \mathrm{~g} \mathrm{DW}$ ) amounts of these compounds in $S$. macrocarpon leaves (Haliński et al. 2015). Possibly, their amount depends on the growing conditions and processing of the plant material. There was no clear association of the sterol content with the cultivation status, and the chemical composition of the fraction was also quite similar in all accessions, with the most abundant $\beta$-sitosterol, stigmasterol and sometimes cycloartenol. Cholesterol, which is quite common in solanaceous plants (Hartmann 1998), was a minor component of the fraction, excluding $S$. anguivi accessions, where it was one of the major sterols.

\section{Anti-nutrient compounds}

The chemical analysis of anti-nutrient compounds included aglycones of steroidal glycoalkaloids and sapogenins liberated from saponins. Identification of the compounds was based on mass spectra of their derivatives as described in Materials and methods; mass spectra of sapogenins were also compared to those obtained for the compounds isolated from fenugreek seeds, which were already characterized (Taylor et al. 1997). Diosgenin, yamogenin, tigogenin and neotigogenin were identified this way: their mass spectra and retention parameters were identical with those recorded for fenugreek samples. Bethogenin was 


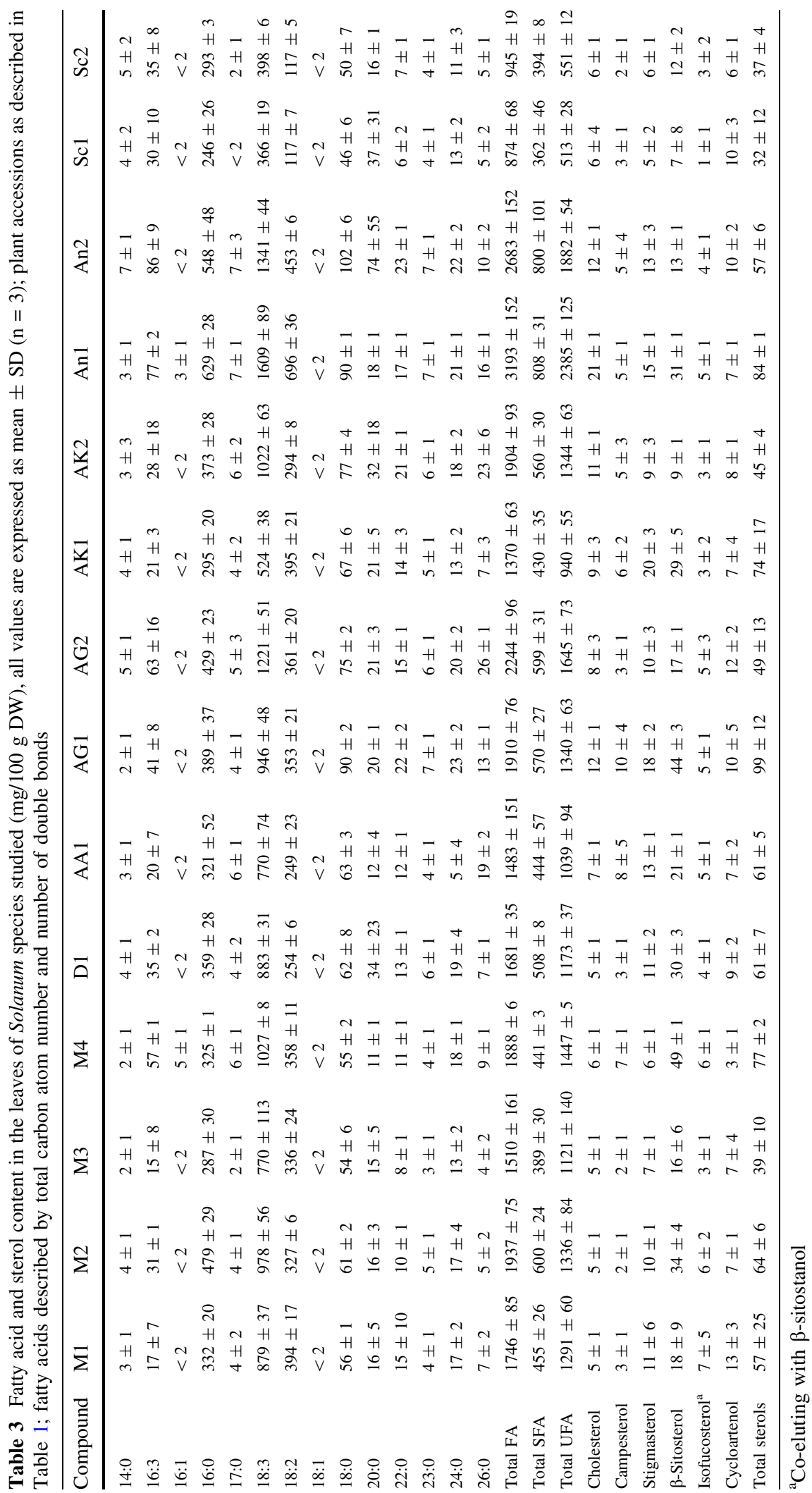


identified basing solely on mass spectrum of its TMSi derivative, which was almost identical with the one reported for the native compound (Akahori et al. 1971), with the base peak at $m / z 139$, a prominent peak at $\mathrm{m} / \mathrm{z}, 198$ and small characteristic signals at $\mathrm{m} / \mathrm{z} 165$ and 180. Moreover, a small signal of molecular ion was also recorded at $\mathrm{m} / \mathrm{z} 516$ as expected. Two other sapogenins, which were detected only in S. scabrum extracts, remained unidentified. One of them, marked as "sapogenin 2", displayed a mass spectrum very similar to the one recorded for bethogenin, but with the signal of molecular ion at $\mathrm{m} / \mathrm{z} 518$, suggesting a saturated analogue of the latter. It was, however, impossible to confirm basing on the experiments conducted. Mass spectral data for each compound detected in extracts from solanaceous plants studied are given as Supplementary material (Table S1), and the results of quantitative analysis are shown in Table 4. Two distinct groups of plant species could be separated basing on the results. The first group included only $S$. macrocarpon and its wild ancestor $S$. dasyphyllum and was characterized by the presence of solasodine and absence of any sapogenins. The presence of solasodine in $S$. macrocarpon leaves is not surprising, as potentially unsafe amounts of two solasodine-based glycoalkaloids (solasonine and solamargine) were already reported in fruits of this species (Sánchez-Mata et al. 2010). The aglycone remained unidentified in the previous study (Haliński et al. 2015), where only trimethylsilylation was performed prior to GC-MS analysis, supporting the need of twostep derivatization in the analysis of tomatidine-like aglycones (Laurila et al. 1999). The solasodine content in leaves was relatively low and varied from 3 to $55 \mathrm{mg} / 100 \mathrm{~g}$ DW. When the results were re-calculated for the solamargine content (which was the main glycoalkaloid in $S$. macrocarpon fruits as reported by Sánchez-Mata et al. 2010), the respective amounts were $14-211 \mathrm{mg} / \mathrm{kg} \mathrm{FW}$. The upper safety limit was already suggested for potato glycoalkaloids at the level of $200 \mathrm{mg} / \mathrm{kg} \mathrm{FW}$ (Mensinga et al. 2005), and in most cases solasodine-based glycoalkaloid content in S. macrocarpon leaves fell within the acceptable range, with the only exception of $S$. macrocarpon var. sapinii (CGN17504; M4). The second group of plants included all remaining species ( $S$. aethiopicum, S. anguivi and S. scabrum); no presence of solasodine or any other aglycone of steroidal glycoalkaloids was confirmed in these plants. They all, however, produced 
significant amounts of sapogenins. Diosgenin was identified in all accessions of above-mentioned species and was the main fraction component in all S. aethiopicum and S. anguivi accessions, followed by minor amounts of yamogenin and-in several casesalso bethogenin and tigogenin. The main sapogenin of S. scabrum was, on the other hand, tigogenin, with disogenin, neotigogenin and two unidentified compounds as the minor fraction components. The amounts of sapogenins varied broadly between species and also between accessions of a single species. Two S. anguivi accessions had 29 and $412 \mathrm{mg}$ of sapogenins/100 g DW. Similarly, in leaves of S. aethiopicum group Gilo accessions, these values were 2 and $240 \mathrm{mg} / 100 \mathrm{~g}$ DW. Surprisingly, in S. aethiopicum group Kumba, bearing edible leaves, the amounts of sapogenins were much higher and reached values of $388-403 \mathrm{mg} / 100 \mathrm{~g}$ DW. Finally, more distant taxonomically and much less domesticated S. scabrum displayed the highest sapogenin content, which varied between 640 and $1040 \mathrm{mg} / 100 \mathrm{~g} \mathrm{DW}$. The lack of solasodine in $S$. aethiopicum leaves is somehow surprising, as small amounts of solasodine-based glycoalkaloids were reported in fruits of this species (Sánchez-Mata et al. 2010). Also, while there were some reports suggesting the presence of saponins in $S$. aethiopicum leaves, it was not fully documented until now. Saponins were reported in $S$. anguivi fruits (Honbu et al. 2002), but not leaves. These compounds were, however, based on sapogenins different than those reported in the current study. As far as we concerned, there are no reports clearly proving the presence of saponins in S. scabrum leaves.

Changes in chemical composition during plant domestication

The current study is the first approach to describe some of the biochemical changes occurring during the initial stage of plant domestication within species used as a source of edible leaves. Moreover, it targets several species from the Solanum genus, which are expected to produce significant amounts of potentially toxic steroidal glycoalkaloids and/or saponins, hence allowing not only evaluation of changes in nutritional value, but also a risk associated with consumption of suchonly partially domesticated-plants (Milner et al. 2011). The main hypothesis assumed that changes in the amounts of both nutrients and anti-nutrients are driven by a kind of conscious selection; this type of selection seems, however, to be restricted to advanced breeding with full scientific background. In case of only semi-domesticated plants, selection was possibly based on other plant characteristics, like number of prickles, overall morphology of the plant or-in case of plants grown for fruits, also their shape, size and colour. A simple comparison of plant morphology (Figures S1-S3) somehow supports the most probable assumption that the selection was primarily based on the reduction of the mechanical means of protection. It was suggested for some other solanaceous plant species, that the initial conscious selection of wild plants for possible further cultivation could be based on number and size of prickles covering plants (Heiser 1988). In case of $S$. dasyphyllum-S. macrocarpon complex, this type of selection seems very probable, as the reduction in number and size of prickles in cultivated plants was quite obvious and was previously reported (Lester and Daunay 2001). While it was also already suggested that both plants are in fact different morphological forms of a single species (Bukenya and Carasco 1994; Haliński et al. 2017), and that intermediate forms occur (Lester and Daunay 2001), it could be assumed that the selection was directed simply to obtain plants lacking prickles, which is of special importance in case of leafy vegetables. Similar mechanism was, however, not confirmed for the sister species complex $S$. anguivi-S. aethiopicum, where prickles were not found, neither in wild $S$. anguivi nor in cultivated $S$. aethiopicum plants from Gilo and Kumba groups. Surprisingly, an excessive number of prickles was found in S. aethiopicum group Aculeatum, which was probably originated in Europe as a hybrid between $S$. anguivi and S. aethiopicum Kumba (Lester and Daunay 2001). Wild S. anguivi was in the past reported as "very prickly", while the supposed intermediate form between $S$. anguivi and cultivated $S$. aethiopicum was lacking prickles and was described as S. distichum (Lester and Daunay 2001). While no prickles were found in $S$. anguivi accessions in the current study, it could only be supposed that so-called $S$. distichum was in fact a non-prickly form of $S$. anguivi, which could be initially used for the cultivation in order to obtain domesticated plants with no prickles. This, however, needs to be confirmed. Much different $S$. scabrum plants were lacking any extensive mechanical means of protection: this plant species is more related to a common $S$. nigrum than to any 


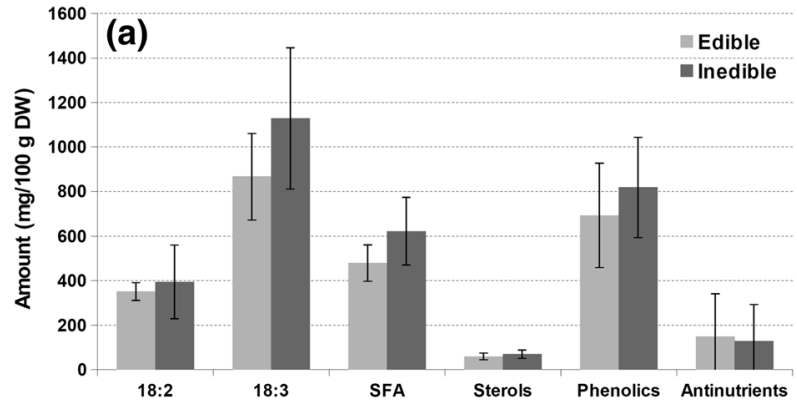

Fig. 2 Overview of the results obtained for unsaturated (18:2, 18:3) and saturated (SFA) fatty acids, sterols, phenolic compounds (as GAE) and anti-nutrients in leaves of $S$. macrocarpon, $S$. dasyphyllum, S. aethiopicum and $S$. anguivi: a comparison of the results for plants with edible ( $S$. macrocarpon, S. aethiopicum group Kumba; $\mathrm{n}=6$ ) and inedible

species of African eggplant. It was already shown that S. scabrum plants of different morphology and domestication status are similar genetically (Manoko et al. 2008). Therefore, all accessions of this plant species could be assumed as belonging to a single species on the very initial stage of domestication process in even greater extent than in case of the gboma and scarlet eggplants.

The analysis of total phenolic compounds, fatty acids and sterols in leaves of plant species studied did not support the hypothesis assuming a conscious selection of plants of higher nutritional values. There was no clear difference between wild and cultivated species, as well as between plants with edible and inedible leaves. The only exception was a much higher content of fatty acids in wild $S$. anguivi accessions when compared to cultivated $S$. aethiopicum plants. The more detailed analysis of the results revealed that within the African eggplant complex ( $S$. anguivi-S. aethiopicum, S. dasyphyllum-S. macrocarpon) plants with inedible leaves produced slightly higher amounts of saturated and unsaturated fatty acids and total phenolic compounds (Fig. 2a). None of this differences was, however, statistically significant. The comparison of both groups of plant species suggested that $S$. anguivi-S. aethiopicum complex is more valuable source of phenolic compounds (Fig. 2b): their content was significantly higher ( $t$ test, $P \leq 0.05$ ) in scarlet eggplant than in $S$. dasyphyllum-S. macrocarpon complex. On the other hand, while the latter produced only moderate amounts of solasodine-based glycoalkaloids (which were, in general, more

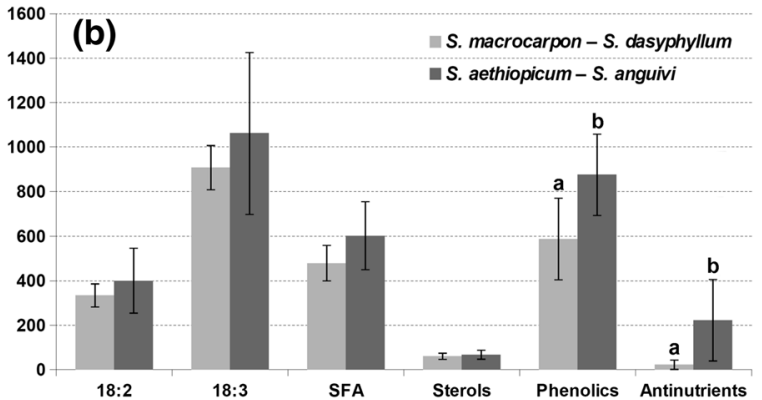

(S. dasyphyllum, S. aethiopicum groups Gilo and Aculeatum, $S$. anguivi; $\mathrm{n}=6$ ) leaves; $\mathbf{b}$ comparison of the results for $S$. macrocarpon-S. dasyphyllum $(\mathrm{n}=5)$ and $S$. aethiopicum-S. anguivi $(\mathrm{n}=7)$ complexes; the results marked with different letters are significantly different from one another ( $t$ test, $P \leq 0.05)$

abundant in domesticated $S$. macrocarpon), some of the scarlet eggplant accessions displayed much higher content of anti-nutrient sapogenins. The average content of anti-nutrient compounds was significantly higher in $S$. anguivi-S. aethiopicum complex. The remaining $S$. scabrum was excluded from this comparison due to much different taxonomical position and cultivation status. It was, however, already mentioned that it had the highest amounts of antinutrient compounds and in the same time low amounts of unsaturated fatty acids and phenolic compounds. Because all $S$. scabrum forms, including wild and semi-cultivated plants, could be treated as genetically uniform, this plant species at its current stage of domestication should be used with caution.

The differences in the nutritional value between the wild and domesticated plants were already reported for several species from other families. For example, wild rice (Oryza rufipogon L.) displayed higher antioxidant activity and much higher content of tocopherols and tocotrienols when compared to the cultivated rice (Fasahat et al. 2012). The wild progenitor of the finger millet (Eleusine coracana (L.) Gaertn.) was reported as a rich source of protein, fat and minerals; it also contained a higher amount of essential amino acids when compared to the cultivated plants (Barbeau and Hilu 1993). Little is known about changes in nutritional value of leafy vegetables in comparison to their wild relatives, but basing on the currently reported results, it can be assumed that-at least in solanaceous plants-similar effects may occur, like in case of fatty acid content in $S$. anguivi 
and $S$. aethiopicum. The opposite scenario, which would support the hypothesis assuming conscious selection of plants with higher nutritional value, was not confirmed. Similarly, there was no reduction in glycoalkaloid and steroidal saponin content neither in cultivated plants when compared to wild lines nor in plants with edible leaves when compared to those bearing inedible ones. The loss of toxic and/or bitter compounds is often suggested as a change driven by a conscious selection (Heiser 1988). The selection of plants with low amounts of glycoalkalkoids was already suggested as a part of the domestication process of the potato (Johns and Alonso 1990). On the other hand, plants containing lower amounts of toxins would be more susceptible to insect herbivores and plant pathogens, and therefore could be excluded from further cultivation. While it has been shown that there is no trade off between physical and chemical defence in a wide range of plant species (Moles et al. 2012), it cannot be excluded at lower level of organization. Therefore, while the majority of domesticated plants in the current study were lacking mechanical means of protection, it is possible that they were replaced with chemical ones. Such a phenomenon could be observed in genus Lophophora (Cactaceae), where physical defences were largely replaced by the chemical ones and those species with the highest alkaloid content (e.g. L. williamsii) are in the same time the most widely distributed (Dortort 2007; Wink 2016). The results suggest that at the current stage of domestication, solanaceous plants with edible leaves were selected basing on different traits and significant amounts of potentially harmful substances may still be present in their leaves.

\section{Conclusion}

The results of the present study have shown that domestication of plants from Solanaceae family, which are grown for edible leaves, did not result in lowering the amount of potentially harmful glycoalkaloids and saponins. Moreover, unsaturated fatty acids, phytosterols and phenolic compounds were determined in similar amounts in leaves of cultivated and wild plants, or even were more abundant in wild plants. Therefore, hypothesis assuming a conscious selection of plants with higher nutritional values and lower content of toxins was rejected. It is suggested that at the early stage of domestication, selection was made basing mostly on morphological features, with a special attention paid to reduction of mechanical means of protection, like hairs and prickles. Further experiments are required for the identification of the most and the least advanced accessions of each cultivated species, in order to allow a better understanding of mechanisms underlying the domestication of this important group of green leafy vegetables. Screening analysis of more plant traits, including several other classes of nutrients, as well as selection of accessions with the lowest amounts of anti-nutrient compounds, are also of interest. This would give an opportunity to start a breeding program based on more intentional selection, which would be focused mostly on nutritional value and safety of certain plant lines obtained.

\section{Data availability}

The datasets generated during and/or analysed during the current study are available from the corresponding author on reasonable request.

Acknowledgements Financial support was provided by the University of Gdańsk under Grant DS 530-8617-D594-17.

\section{Compliance with ethical standards}

Conflict of interest All authors declare no conflict of interest.

Open Access This article is distributed under the terms of the Creative Commons Attribution 4.0 International License (http:// creativecommons.org/licenses/by/4.0/), which permits unrestricted use, distribution, and reproduction in any medium, provided you give appropriate credit to the original author(s) and the source, provide a link to the Creative Commons license, and indicate if changes were made.

\section{References}

Acquadro A, Barchi L, Gramazio P, Portis E, Vilanova S, Comino C, Plazas M, Prohens J, Lanteri S (2017) Coding SNPs analysis highlights genetic relationships and evolution pattern in eggplant complexes. PLoS ONE 12(7):e0180774. https://doi.org/10.1371/journal.pone. 0180774

Akahori A, Yasuda F, Okanishi T (1971) Steroidal sapogenins of Aletris spicata (Thunb.) Franchet. Chem Pharm Bull 19:2409-2411. https://doi.org/10.1248/cpb.19.2409

Barbeau WE, Hilu KW (1993) Protein, calcium, iron, and amino acid content of selected wild and domesticated cultivars of 
finger millet. Plant Foods Hum Nutr 43:97-104. https://doi. org/10.1007/BF01087914

Blois MS (1958) Antioxidant determinations by the use of a stable free radical. Nature 181:1199-1200. https://doi.org/ 10.1038/1811199a0

Brand-Williams W, Cuvelier ME, Berset C (1995) Use of free radical method to evaluate antioxidant activity. Lebensm Wiss Technol 28:25-30. https://doi.org/10.1016/S00236438(95)80008-5

Brown MS, McDonald GM, Friedman M (1999) Sampling leaves of young potato (Solanum tuberosum) plants for glycoalkaloid analysis. J Agric Food Chem 47:2331-2334. https://doi.org/10.1021/jf981124m

Bukenya ZR, Bonsu KO (2004) Solanum macrocarpon L. In: Grubben GJH, Denton OA (eds.) PROTA (Plant resources of tropical Africa/Ressources végétales de l'Afrique tropicale). Wageningen University, Wageningen

Bukenya ZR, Carasco JF (1994) Biosystematic study of Solanum macrocarpon- $S$. dasyphyllum complex in Uganda and relations with Solanum linnaeanum. East Afr Agric For J 59:187-204. https://doi.org/10.1080/00128325.1994. 11663195

Diamond J (2002) Evolution, consequences and future of plant and animal domestication. Nature 418:700-707. https:// doi.org/10.1038/nature01019

Dortort F (2007) Under discussion: Mexican Oddities Strombocactus, Pelecyphora, Obregonia, Aztekium, Geohintonia and Lophophora. Cactus Succul J 79:21-29. https://doi. org/10.2985/0007-9367(2007)79\%5b21:UD\%5d2.0.CO;2

Fasahat P, Muhammad K, Abdullah A, Ratnam W (2012) Proximate nutritional composition and antioxidant properties of Oryza rufipogon, a wild rice collected from Malaysia compared to cultivated rice, MR219. Aust J Crop Sci 6:1502-1507

Folch J, Lees M, Sloane Stanley GH (1957) A simple method for the isolation and purification of total lipides from animal tissues. J Biol Chem 226:497-509

Gbile ZO, Adesina SK (1988) Nigerian Solanum species of economic importance. Ann Mo Bot Gard 75:862-865. https://doi.org/10.2307/2399374

Glew RS, Amoako-Atta B, Ankar-Brewoo G, Presley J, Chuang LT, Millson M, Smith BR, Glew RH (2010) Furthering an understanding of West African plant foods: mineral, fatty acid and protein content of seven cultivated indigenous leafy vegetables of Ghana. Br Food J 112:1102-1114. https://doi.org/10.1108/00070701011080230

Goad LJ, Akihisa T (1997) Analysis of sterols. Blackie Academic and Professional, London

Haliński ŁP, Puckowski A, Stepnowski P (2015) Glycoalkaloid, phytosterol and fatty acid contents of raw and blanched leaves of the gboma eggplant (Solanum macrocarpon L.). J Food Nutr Res 54:9-20

Haliński ŁP, Samuels J, Stepnowski P (2017) Multivariate analysis as a key tool in chemotaxonomy of brinjal eggplant, African eggplants and wild related species. Phytochemistry 144:87-97. https://doi.org/10.1016/j.phytochem.2017.09. 001

Hartmann MA (1998) Plant sterols and the membrane environment. Trends Plant Sci 3:170-175. https://doi.org/10. 1016/S1360-1385(98)01233-3
Heiser CB (1988) Aspects of unconscious selection and the evolution of domesticated plants. Euphytica 37:77-81. https://doi.org/10.1007/BF00037227

Honbu T, Ikeda T, Zhu XH, Yoshihara O, Okawa M, Nafady AM, Nohara T (2002) New steroidal glycosides from the fruits of Solanum anguivi. J Nat Prod 65:1918-1920. https://doi.org/10.1021/np020254t

Johns T, Alonso JG (1990) Glycoalkaloid change during the domestication of the potato, Solanum section Petota. Euphytica 50:203-210. https://doi.org/10.1007/ BF00023646

Laurila J, Laakso I, Väänänen T, Kuronen P, Huopalahti R, Pehu E (1999) Determination of solanidine- and tomatidine-type glycoalkaloid aglycons by gas chromatography/mass spectrometry. J Agric Food Chem 47:2738-2742. https:// doi.org/10.1021/jf981009b

Lee ST, Stegelmeier BL, Gardner DR (2001) The isolation and identification of steroidal sapogenins in switchgrass. J Nat Toxins 10:273-281

Lester RN, Daunay MC (2001) Diversity of African vegetable Solanum species and its implications for a better understanding of plant domestication. Schriften Genet Resourcen 18:137-152

Lester RN, Seck A (2004) Solanum aethiopicum L. In: Grubben GJH, Denton OA (eds.) PROTA (Plant resources of tropical africa/Ressources végétales de l'Afrique tropicale). Wageningen University, Wageningen

Manoko MLK, van der Berg RG, Feron RMC, van der Weerden GM, Marini C (2008) Genetic diversity of the African hexaploid species Solanum scabrum Mill. and Solanum nigrum L. (Solanaceae). Genet Resour Crop Evol 55:409-418. https://doi.org/10.1007/s10722-0079248-z

Mensinga TT, Sips AJAM, Rompelberg CJM, van Twillert K, Meulenbelt J, van den Top HJ, van Egmond HP (2005) Potato glycoalkaloids and adverse effects in humans: an ascending dose study. Regul Toxicol Pharmacol 41:66-72. https://doi.org/10.1016/j.yrtph.2004.09.004

Meyer RS, DuVal AE, Jensen HR (2012) Patterns and processes in crop domestication: an historical review and quantitative analysis of 203 global food crops. New Phytol 196:29-48. https://doi.org/10.1111/j.1469-8137.2012.04253.x

Milner SE, Brunton NP, Jones PW, O’Brien NM, Collins SG, Maguire AR (2011) Bioactivities of glycoalkaloids and their aglycones from Solanum species. J Agric Food Chem 59:3454-3484. https://doi.org/10.1021/jf200439q

Moles AT, Peco B, Wallis IR et al (2012) Correlations between physical and chemical defences in plants: tradeoffs, syndromes, or just many different ways to skin a herbivorous cat? New Phytol 198:252-263. https://doi.org/10.1111/ nph.12116

Oboh G, Akindahunsi AA (2004) Change in the ascorbic acid, total phenol and antioxidant activity of sun-dried commonly consumed green leafy vegetables in Nigeria. Nutr Health 18:29-36. https://doi.org/10.1177/ 026010600401800103

Plazas M, Andújar I, Vilanova S, Gramazio P, Herraiz FJ, Prohens J (2014a) Conventional and phenomics characterization provides insight into the diversity and relationships of hypervariable scarlet (Solanum aethiopicum L.) 
and gboma (S. macrocarpon L.) eggplant complexes. Front Plant Sci 5:318. https://doi.org/10.3389/fpls.2014.00318

Plazas M, Prohens J, Cuñat AN, Vilanova S, Gramazio P, Herraiz FJ, Andújar I (2014b) Reducing capacity, chlorogenic acid content and biological activity in a collection of scarlet (Solanum aethiopicum) and gboma (S. macrocarpon) eggplants. Int J Mol Sci 15:17221-17241. https://doi. org/10.3390/ijms151017221

Purugganan MD, Fuller DQ (2009) The nature of selection during plant domestication. Nature 457:843-848. https:// doi.org/10.1038/nature07895

San José R, Plazas M, Sánchez-Mata MC, Cámara M, Prohens J (2016) Diversity in composition of scarlet (S. aethiopicum) and gboma (S. macrocarpon) eggplants and of interspecific hybrids between $S$. aethiopicum and common eggplant ( $S$. melongena). J Food Compos Anal 45:130-140. https://doi. org/10.1016/j.jfca.2015.10.009

Sánchez-Mata MC, Yokoyama WE, Hong YJ, Prohens J (2010) Alpha-solasonine and alpha-solamargine contents of gboma (Solanum macrocarpon L.) and scarlet (Solanum aethiopicum L.) eggplants. J Agric Food Chem 58:5502-5508. https://doi.org/10.1021/jf100709g

Singleton VL, Rossi JA (1965) Colorimetry of total phenolics with phosphomolybdic-phosphotungstic acid reagents. Am J Enol Vitic 16:144-158

Stedje B, Bukenya-Ziraba R (2003) RAPD variation in Solanum anguivi Lam. and S. aethiopicum L. (Solanaceae) in Uganda. Euphytica 131:293-297. https://doi.org/10.1023/ A: 1024079208879

Taylor WG, Shahid Zaman M, Mir Z, Mir PS, Acharya SN, Mears GJ, Elder JL (1997) Analysis of steroidal sapogenins from amber fenugreek (Trigonella foenum-graecum) by capillary gas chromatography and combined gas chromatography/mass spectrometry. J Agric Food Chem 45:753-759. https://doi.org/10.1021/jf960200n

Topolewska A, Czarnowska K, Haliński ŁP, Stepnowski P (2015) Evaluation of four derivatization methods for the analysis of fatty acids from green leafy vegetables by gas chromatography. J Chromatogr B 990:150-157. https:// doi.org/10.1016/j.jchromb.2015.03.020

Tsukatani H, Takauchi K, Yoshida J, Yamada S, Tokumura A, Hamaguchi C (1985) Isolation of diosgenin [(25R)-spirost5-en-3ß-ol] from a lysate of a new hypotensive phospholipid occurring in bovine brain. J Neurochem 44:658-661. https://doi.org/10.1111/j.1471-4159.1985.tb05463.x

Turkmen N, Sari F, Velioglu YS (2005) The effect of cooking methods on total phenolics and antioxidant activity of selected green vegetables. Food Chem 93:713-718. https:// doi.org/10.1016/j.foodchem.2004.12.038

Uusiku NP, Oelofse A, Duodu KG, Bester MJ, Faber M (2010) Nutritional value of leafy vegetables of sub-Saharan Africa and their potential contribution to human health: a review. J Food Compos Anal 23:499-509. https://doi.org/10.1016/ j.jfca.2010.05.002

Vorontsova MS, Knapp S (2018) Solanum dasyphyllum Schumach. \& Thonn. In: Solanaceae Source. http:// solanaceaesource.org/taxonomy/term/106519/ descriptions. Accessed 16 Aug 2018

Wink M (2016) Secondary metabolites: deterring herbivores. In: eLS, John Wiley \& Sons, Ltd. https://doi.org/10.1002/ 9780470015902.a0000918.pub3

Zohary D (2004) Unconscious selection and the evolution of domesticated plants. Econ Bot 58:5-10. https://doi.org/10. 1663/0013-0001(2004)058\%5b0005:USATEO\%5d2.0. $\mathrm{CO} ; 2$ 